\title{
Resveratrol ameliorates 2,4-dinitrofluorobenzene-induced atopic dermatitis-like lesions through effects on the epithelium
}

Sule Caglayan Sozmen, Meral Karaman, Serap Cilaker Micili, Sakine Isik, Zeynep Arikan Ayyildiz, Alper Bagriyanik, Nevin Uzuner, Ozkan Karaman

Background: Resveratrol is a natural polyphenol that exhibits anti-inflammatory effects. The aim of this study was to investigate the effects of resveratrol treatment on epitheliumderived cytokines and epithelial apoptosis in a murine model of atopic dermatitis-like lesions. Material and methods: Atopic dermatitis-like lesions were induced in BALB/C mice by repeated application of 2,4-dinitrofluorobenzene to shaved dorsal skin. Twentyone BALB/c mice were divided into three groups: group I (control), group II (vehicle control), and group III (resveratrol). Systemic resveratrol (30 mg/kg/day) was administered repeatedly during the $6^{\text {th }}$ week of the experiment. After the mice had been sacrificed, skin tissues were examined histologically for epithelial thickness. Epithelial apoptosis (caspase3) and epithelium-derived cytokines [interleukin (IL)-25, IL-33, and thymic stromal lymphopoietin (TSLP)] were evaluated immunohistochemically. Results: Epithelial thickness and the numbers of IL-25, IL-33, TSLP and caspase-3-positive cells were significantly higher in group II compared to group I mice. There was significant improvement in epithelial thickness in group III compared with group II mice $(p<0.05)$. The numbers of IL-25, IL-33, and TSLP-positive cells in the epithelium were lower in group III than in group II mice $(p<0.05)$. The number of caspase-3-positive cells, as an indicator of apoptosis, in the epithelium was significantly lower in group III than in group II mice $(p<0.05)$. Conclusion: Treatment with resveratrol was effective at ameliorating histological changes, inflammation by acting on epithelium-derived cytokines and epithelial apoptosis. 
1 Resveratrol ameliorates 2,4-dinitrofluorobenzene-induced atopic dermatitis-like lesions

2 through effects on the epithelium

3

4 Sule Caglayan Sozmen ${ }^{1}$, Meral Karaman ${ }^{2}$, Serap Cilaker Micili ${ }^{3}$, Sakine Isik ${ }^{1}$, Zeynep Arikan

5 Ayyildiz¹,Alper Bagriyanik ${ }^{3}$, Nevin Uzuner $^{1}$, Ozkan Karaman $^{1}$

6

7

8 1Dokuz Eylul University Faculty of Medicine, Department of Pediatrics, Division of Pediatric

9 Allergy and Immunology,Izmir,Turkey

${ }^{2}$ Dokuz Eylul University Faculty of Medicine, Department of Medical Microbiology, Izmir, Turkey

11 3Dokuz Eylul University Faculty of Medicine, Department of Histology and Embriology, Izmir, 12 Turkey

Corresponding Author,

Sule Caglayan Sozmen ${ }^{1}$

Dokuz Eylul University Faculty of Medicine, Department of Pediatrics, Division of Pediatric

17 Allergy and Immunology,35340,Inciralti-Izmir

E-mail address:sulecaglayan07@yahoo.com 


\section{Resveratrol ameliorates 2,4-dinitrofluorobenzene-induced atopic dermatitis-like lesions through effects on the epithelium}

\section{Introduction}

Atopic dermatitis (AD) is a chronic inflammatory skin disease primarily affecting children. Its prevalence has been steadily increasing during the last decade in both developed and developing countries (Bieber 2008). Although the etiology of AD remains obscure, interplay among immunological, environmental, and genetic factors leads to its development (Boguniewicz \& Leung 2011). However, no current treatment for AD can ameliorate its pathogenesis permanently.

The pathogenesis of AD has not been clearly identified, but most information about its immunological features has been obtained in recent years. It was demonstrated that the epidermal cells in $\mathrm{AD}$ are unique in terms of both their barrier and immunological properties. The epidermis of patients with $\mathrm{AD}$ exhibits significant barrier disruption and prominent keratinocyte pathology. Keratinocytes are specialized epithelial cells in skin tissue that contribute to the initiation and maintenance of the inflammatory process in $\mathrm{AD}$ and are capable of producing, as well as responding to, various inflammatory mediators (Esche et al. 2004). Interleukin (IL)-25, IL-33, and thymic stromal lymphopoietin (TSLP) are mainly released from keratinocytes and promote the Th2-type immune response (Brandt \& Sivaprasad 2011). Dysregulated apoptosis of keratinocytes plays a major role in the pathogenesis of AD by causing spongiosis and intercellular edema, leading to impaired epithelial integrity (Trautmann et al. 2000).

Resveratrol is a naturally occurring polyphenol found in various types of fruits and vegetables, most notably in the skin of red grapes. Several studies indicated that it exerts various pharmacological effects, such as anticancer, antioxidant, antiangiogenic, and anti-inflammatory properties(Harikumar \& Aggarwal 2008). In this context, we investigated the effects of resveratrol treatment on keratinocyte-derived cytokines and keratinocyte apoptosis using a murine model of 2,4-dinitrophenylbenzene (DNFB)-induced AD-like lesions. 
54

55

56

57

58

59

60

61

62

63

64

65

66

67

68

69

70

71

72

73

74

75

76

77

78

79

80

81

82

\section{Materials and Methods}

\section{Animals}

Twenty-one 6-8-week-old male BALB/c mice weighing 18-20 g, purchased from the Department of Multidisciplinary Animal Laboratory, Dokuz Eylul University (Izmir, Turkey), were used in this study. The animals were kept in hygienic macrolane cages in air-conditioned rooms under 12-h light/dark cycles for the experiment. Food and water were provided ad libitum in a pathogenfree laboratory in the same department. All experimental procedures complied with the requirements of the Dokuz Eylul University Animal Care and Ethics Committee(Registration number:92/2013)

\section{Induction of dermatitis}

The induction of AD by using DNFB was established based on previous research (Li et al. 2013). DNFB was purchased from Sigma Chemical (St. Louis, MO, USA) and dissolved in a mixture of acetone and olive oil (4:1). AD-like skin lesions were evoked by repeated application of $100 \mu \mathrm{L}$ of $0.5 \%$ DNFB to the shaved backs of mice during the first week for sensitization (Figure 1). After the first week, $100 \mu \mathrm{L}$ of $0.2 \%$ DNFB was applied twice a week for a further 4 weeks The lesions developed at the end of the $5^{\text {th }}$ week. During the $6^{\text {th }}$ week, DNFB was applied once to maintain inflammation.

\section{Experimental Schedule}

The $21 \mathrm{BALB} / \mathrm{c}$ mice were randomly divided into three groups ( $\mathrm{n}=7$ per group), as follows: group I (control), group II (vehicle control), and group III (treatment with resveratrol) (Figure 1).

The acetone and olive oil mixture was applied to shaved back of group I (control) without DNFB in the same manner. Atopic dermatitis -like lesions were induced in Group II (vehicle control) and group III (treatment with resveratrol).

Resveratrol was given to group III (treatment with resveratrol) at a dose of $30 \mathrm{mg} / \mathrm{kg} /$ day for 7 days during the $6^{\text {th }}$ week. Resveratrol was administered to each mice after dissolved in $100 \mu \mathrm{L}$ dimethyl sulfoxide (DMSO) in group III (Lee et al. 2009; Sharma et al. 2014 (Johnson et al. 2011)). Resveratrol was purchased from Sigma-Chemical (St.Louis,MO,USA). Group II (vehicle control group) was treated with $100 \mu 1$ DMSO during the $6^{\text {th }}$ week of experimental procedure Saline $(0.9 \%$ 
$83 \mathrm{NaCl}$ ) was administered to group I (control group) at dose of $100 \mu 1$ during $6^{\text {th }}$ week. All drugs 84 were administered via the orogastric route. The mice were weighed beginning of the experiment, 85 at the end of the $5^{\text {th }}$ and $6^{\text {th }}$ week.

86 Animals were sacrificed by an overdose of ketamine $24 \mathrm{~h}$ after the last drug administration, and 87 dorsal skin samples were obtained for histomorphological analysis.

\section{Evaluation of dermatitis}

Severity of dermatitis was estimated macroscopically at the end of $5^{\text {th }}$ and $6^{\text {th }}$ weeks. The following scoring procedure was applied:0,no symptoms; 1,mild symptoms; 2 ,moderate symptoms; 3 ,severe symptoms. The dermatitis score was described as the sum of the scores for erythema/hemorrhage,edema, excoriation/erosion and scaling/dryness(Hanifin et al. 2001).

\section{Histomorphological analysis}

Skin samples were placed in buffered formalin for light microscopic evaluation. After fixation, skin samples were embedded in paraffin for light microscopic evaluation and 5- $\mu \mathrm{m}$ serial sections were obtained with a rotary microtome (Leica RM2125; Leica Biosystems, Wetzlar, Germany). The samples were then stained with hematoxylin and eosin. Using these samples, general tissue features were examined and the thickness of the epithelium was measured. Photomicrographs were taken with an Olympus DP70 camera (Olympus, Tokyo, Japan), which was adapted on an Olympus BX51 model microscope (Olympus Optical, Tokyo, Japan). The photomicrographs were taken randomly from five fields of each section. A counting frame was randomly placed four times on the image analyzer system monitor, epithelial thickness was measured (UTHSCA Image Tool for Windows, version 3.0), and the average was taken.

\section{Immunohistochemical detection}

All sections were incubated in a solution of $3 \% \mathrm{H}_{2} \mathrm{O}_{2}$ for 5 min to inhibit endogenous peroxidase activity and then in normal serum blocking solution. Sections were incubated in a humid chamber for $18 \mathrm{~h}$ at $4{ }^{\circ} \mathrm{C}$ with IL-33 monoclonal antibody at 1:100 (anti-IL-33 mouse monoclonal antibody, NBP1-75516; Novus Biologicals, Littleton, CO, USA), IL-25 monoclonal antibody at 1:100 (antiIL-25 mouse monoclonal antibody, NBP1-72027; Novus Biologicals), TSLP monoclonal antibody at 1:100 (anti-TSLP mouse monoclonal antibody, NBP1-76754; Novus Biologicals), and anticaspase-3 antibody at 1:100 (AB3623; Millipore, Billerica, MA, USA). Sections were incubated with biotinylated $\mathrm{IgG}$, followed by streptavidin conjugated to horseradish peroxidase for $15 \mathrm{~min}$, each prepared in accordance with the manufacturer's instructions (85-9043; Invitrogen 
114 Corporation, Camarillo, UK). Sections were finally stained with diaminobenzidine (1718096;

115 Roche, Mannheim, Germany), counter-stained with Mayer's hematoxylin, and analyzed using a

116 light microscope. (Micili et al. 2013).

\section{Semi-quantification of immunostaining}

118 For each animal two adjacent sections were taken. Five images per section/animal were evaluated

119 and the average immunoscoring of these images were calculated. Each section was graded by two

120 blinded histologists to maintain consistency of the scoring system. A grading system was used to

121 score the quantity of anti-IL-33, anti-IL-25, anti-TSLP, anti-caspase-3 positive staining in the

122 sections. Semi-quantitative score was defined as follows: mild $(+)$, moderate $(++)$, strong $(+++)$

123 and very strong $(++++)$ brown staining. Staining intensity was graded semiquantitatively using

$124 \mathrm{H}$-scores, which were calculated using the following equation: $\mathrm{H}$-score $=\Sigma \mathrm{Pi}(\mathrm{i}+1)$, where $\mathrm{i}$ was

125 equal to the intensity of immunohistochemical staining with a value of 1-4, and Pi was the

126 percentage of epithelial cells stained with each intensity, varying between 0-100\%(Yuksel et al. 127 2008).

Statistical analysis

130

131

132

133

134

135

136

137

138

139

140

Values are presented as the mean \pm standard deviation (SD). Normality of the distribution was assessed using the Kolmogorov-Smirnov test. The measurements followed a non-normal distribution, therefore non-parametric comparisons were made by the Kruskal-Wallis test. Pairwise comparisons were made using the Mann-Whitney U-test. A p value less than 0.05 was considered significant.

\section{Results}

\section{Dermatitis score and body weight}

All mice developed AD-like lesions with repeated DNFB challenge in both group II and III at the end of $5^{\text {th }}$ week. The application of DNFB to the shaved back of mice firstly induced erythema and hemorrhage, then edema, erosion, excoriation, dryness and scaling appeared. Dermatits scores 
141 were not significantly different between groups.Treatment with resveratrol during $6^{\text {th }}$ week

142 resulted a decreased dermatitis score in group III that is significantly lower compared to group II 143 (Table 1, Figure 2). There was no significant difference between groups in aspect of body weight 144 gain (data not shown).

\section{Histological evaluation}

146 Epidermal thickness was significantly greater in group II $(97.39 \pm 23.26 \mu \mathrm{m})$ than in group I $147(20.28 \pm 1.15 \mu \mathrm{m})(\mathrm{p}<0.05)$, indicating that the model for AD-like skin lesions had been successfully 148 establishedFigure 3, Figure 4). Epidermal thickness was significantly lower in group III $149(40.72 \pm 12.66 \mu \mathrm{m})$ than in group II $(\mathrm{p}<0.05)$ ( Figure 3,Figure 4).).

150

151

152

153

154

155

156

157

158

159

160

161

162

163

164

165

166

167

168

\section{Immunohistochemical analysis}

The number of IL-25 positive cells per field in the skin biopsy were significantly higher in group II than in group I $(\mathrm{p}<0.05)$ (Table 2, Figure 5(A,B), Figure 6). The number of IL-33 positive cells in skin tissue were significantly higher in group II than in group I ( $p<0.05)$ (Table 2, Figure 5(D,E), Figure 6).The number of TSLP positive cells in skin tissue were significantly higher in group II compared to group I (Table 2,Figure 5(G,H), Figure 6). The number of caspase-3-positive cells, as an indicator of apoptosis, was significantly higher in group II than in group I in skin biopsy $(\mathrm{p}<0.05)$ (Table 1, Figure 5(J,K), Figure 6).

The number of IL-25 positive cells were significantly lower in group III compared to group II in skin biopsy (Table 2,Figure 5(B,C), Figure 6). IL-33 positive cells significantly lower in group III compared to group II (Table 2,Figure 5(E,F), Figure 6) in skin tissue. Number of TSLP positive cells in skin biopsy were lower in group III in compared to group II (Table 2,Figure 5(H,I), Figure 6). The number of caspase-3-positive cells in skin biopsy was lower in group III than in group II (Table 1, Figure 5(K,L), Figure 6).

\section{Discussion}

Atopic dermatitis is a relapsing, highly pruritic chronic inflammatory disease of the skin that is associated with significant morbidity and has deleterious effects on the quality of life of patients. It also places a substantial financial burden on both the patient's family and society. The clinical presentation of $\mathrm{AD}$ includes erythematous, pruritic, and lichenified skin on some parts of the body 
169 (Lee \& Detzel 2015). The early onset of AD in infancy often triggers the atopic march, which leads

170 to the sequential development of asthma and allergic rhinitis. It is thus the initial step towards 171 subsequent allergic diseases, therefore making an accurate diagnosis and providing appropriate 172 treatment are critical. The pathophysiology of the disease is complex, as it involves impaired 173 epidermal barrier function, a T-cell-mediated inflammatory skin reaction, and accompanying 174 keratinocyte apoptosis (Werfel 2009). The mainstay therapies of AD are topical emollients to 175 provide an effective epidermal barrier, the avoidance of triggers, and anti-inflammatory therapy 176 with topical corticosteroids (TCSs) or topical calcineurin inhibitors (TCIs) (Weidinger \& Novak 177 2015). However, regular long-term use of TCSs can lead to suppression of the hypothalamic178 pituitary-adrenal axis, growth retardation in children, glaucoma, and skin atrophy, while the use 179 of TCIs might increase the risk of lymphoma (Dhar et al. 2014; Hui et al. 2009). Besides these side 180 effects, in a subgroup of patients with severe AD, these topical therapies are insufficient to control 181 symptoms, therefore systemic treatment options become necessary. Immunosuppressant agents 182 such as systemic corticosteroids, cyclosporine, and azathioprine should be considered in case the 183 disease activity cannot be adequately controlled with conventional topical treatments. These 184 systemic treatments can have serious, even life-threatening adverse effects, mainly due to immunosuppression (Ricci et al. 2009). However, there is still no cure for AD, therefore new 186 systemic treatment options with minimal side effects are in demand.

187 In this study, we investigated the effects of resveratrol on epidermal thickness, keratinocyte 188 apoptosis, and keratinocyte-derived cytokines on AD-like skin lesions. We examined the thickness of the epithelium and immunohistochemical staining of IL-25, IL-33, and TSLP antibodies to assess the severity of inflammation; we also used immunohistochemical analysis of caspase-3 to assess apoptosis. In this study, we found that resveratrol was effective at ameliorating AD-like lesions by controlling keratinocyte-derived inflammation and keratinocyte apoptosis.

In previous research, the role of resveratrol as a treatment modality for allergic diseases was investigated, and many important biological pathways were identified through animal studies. Resveratrol exerted anti-inflammatory effects on a murine model of eosinophilic chronic rhinosinusitis with nasal polyps by inhibiting lipoxygenase pathway and eosinophil recruitment (Kim et al. 2013). Treatment with systemic resveratrol improved chronic structural airway changes 198 such as subepithelial extracellular matrix thickness and fibrosis, with decreased expression of 
199 transforming growth factor beta-1 (TGF- $\beta 1$ ) (Royce et al. 2011). Resveratrol treatment also caused 200 decreased mast cell degranulation and allergic inflammation by suppressing monocyte chemotactic 201 protein-1 and macrophage inflammatory protein-2 in a mouse model of passive cutaneous 202 anaphylaxis (Han et al. 2013). In a murine model of asthma, resveratrol treatment showed 203 beneficial effects on mitochondrial function and attenuated oxidative stress (Reddy 2011). A recent 204 experimental study investigated the effects of resveratrol on house-dust-mite-induced AD in mice, showing that resveratrol treatment down-regulated high-mobility group box (HMGB)1, which is secreted by various immune cells and acts as an important mediator in chronic inflammatory diseases. HMGB1 binds to its receptor, which in turn activates nuclear factor kappa-light-chainenhancer of activated B cells $(\mathrm{NF} \kappa \mathrm{B})$. It was thus suggested that $\mathrm{NF} \kappa \mathrm{B}$ may play a role in the transformation of environmental insults into inflammation in skin tissue (Karuppagounder et al. 2014). Although all of these studies have shown that resveratrol has many favorable effects on allergic diseases, to the best of our knowledge, no studies have investigated its effects on keratinocyte-derived cytokines and keratinocyte apoptosis in experimental AD-like lesions.

Atopic dermatitis is elicited by the interplay between various cell types, including T-cells, Langerhans cells, basophils, eosinophils, and keratinocytes. Among these cell types, keratinocytes have attracted more attention in the pathogenesis of $\mathrm{AD}$ due to their roles in skin barrier function and their contribution to the initiation and maintenance of inflammation (Holgate 2007). Epidermal thickening is obvious in chronic skin lesions of $\mathrm{AD}$, as demonstrated clinically with lichenified plaques and microscopically with acanthosis. Wu et al. found that resveratrol inhibited normal human epidermal keratinocytes by down-regulating aquaporin-3 in a concentration-dependent manner (Wu et al. 2014). In our study, resveratrol treatment led to smaller epidermal thickness, provided a regular epithelium, and produced clinical improvements in AD-like skin lesions.

There has been more supporting evidence that keratinocytes act as true innate immune cells. Keratinocytes secrete several inflammatory mediators that exert a variety of local and distant effects (Esche et al. 2004). IL-25, IL-33, and TSLP are generated by epithelial cells including keratinocytes as well as other cells, and considerable evidence has suggested that these cytokines play a crucial role in the induction of both innate and adaptive Th2 responses.

227 The pathologic mechanism behind AD begins with the processing of allergens by local dendritic cells (DCs), which migrate into draining lymph nodes. These DCs initiate the differentiation of 
229 prime naive allergen-specific CD4 cells into Th2 lymphocytes, which secrete various cytokines 230 (Leung et al. 2004). In this context, the following question arose: How do these DCs become 231 activated to start inflammation in AD? It was shown that TSLP released from keratinocytes could 232 be an activator of DCs. In addition, TSLP has been demonstrated to support the migration, 233 maturation, and activation of DCs in AD skin lesions. Infectious agents and their products, 234 allergens, trauma, and some cytokines, could induce TSLP expression in skin cells. TSLP receptors 235 have been identified on cell types involved in immunological responses, such as T-cells, B-cells, 236 monocytes, mast cells, and natural killer cells (Cianferoni \& Spergel 2014). The role of TSLP in 237 AD pathogenesis has been investigated in many studies. Yoo et al. found that overexpression of 238 TSLP in the epidermis led to an AD-like disease in mice (Yoo et al. 2005). It was also reported 239 that single nucleotide polymorphisms of TSLP and its receptors are associated with AD 240 (Hunninghake et al. 2010). The role of TSLP in AD was demonstrated when increased TSLP levels 241 were observed in lesional skin of AD patients, but not in either nickel-induced contact allergic 242 dermatitis or in skin changes associated with lupus erythematosus (Soumelis et al. 2002). In our 243 study, the number of cells that stained positively for the TSLP antibody was increased in AD-like 244 lesions, demonstrating that these lesions resemble AD. In another mouse model, deficiency in 245 notch signaling, which is an important regulator of skin epidermal integrity in keratinocytes, 246 resulted in chronic skin changes and caused high levels of TSLP in keratinocytes (Dumortier et al. 247 2010). In addition to the many studies suggesting a critical role for TSLP in the 248 immunopathogenesis of $\mathrm{AD}$, it has attracted substantial attention as a therapeutic target. It was 249 shown that a traditional Korean medicine known as Naju Jjok inhibited the expression of TSLP by 250 blocking the caspase-1 signaling pathway in DNFB-induced AD-like lesions (Han et al. 2014a). 251 Another natural anti-inflammatory agent, tryptanthrin, suppressed TSLP in 2,4-DNFB-induced 252 AD-like skin lesions of NC/Nga mice and inhibited the mRNA expression of TSLP through 253 blockade of the receptor-interacting protein 2/caspase-1/nuclear factor- $\kappa \mathrm{B}$ pathway in an activated 254 human mast cell line (Han et al. 2014b). Against this background, we hypothesized that resveratrol, 255 which has been shown to be an anti-inflammatory molecule, might affect this key cytokine of AD. 256 In our study, systemic resveratrol treatment was associated with lower expression of TSLP in AD257 like skin lesions.

258 IL-33 is a member of the IL-1 cytokine family. Allergens, microbes, and pro-inflammatory 259 cytokines can trigger the release of IL-33 from the epidermal barrier (Cevikbas \& Steinhoff 2012). 
260 Its receptor, ST2, presents on various cells including innate lymphoid cells, contributing to the 261 initiation and maintenance of allergic inflammation. It has been shown that ST2 gene 262 polymorphisms are related to the presence of AD and the IL-33-ST2 complex plays a crucial role 263 in AD pathogenesis (Shimizu et al. 2005). Transgenic mice with increased skin-specific expression 264 of IL-33 developed AD-like cutaneous manifestations through the activation of innate lymphoid 265 cells in the skin and lymph nodes (Imai et al. 2013). In addition, Savinko et al. found increased 266 expression of IL-33 in the epidermis of AD patients (Savinko et al. 2012). Although these previous 267 studies clearly suggested a pivotal role for IL-33 in the pathogenesis of AD, to our knowledge, this 268 is the first study to investigate the effects of resveratrol on IL-33 expression in AD-like lesions. In 269 our study, resveratrol treatment resulted in lower immunohistochemical expression of IL-33 in the 270 epidermis of AD-like skin lesions compared with that in a placebo group. This finding may provide 271 a treatment option by suppressing one of the initiators of inflammation in AD.

272 IL-25 is a member of the IL-17 cytokine family that is expressed in epithelial cells in response to 273 proteases such as allergen proteases, trypsin, and papain. It was reported that administration of IL27417 to mice promoted allergic inflammation by inducing IL-4, IL-5, and IL-13 gene expression 275 (Fort et al. 2001). Moreover, DCs activated by TSLP enhance allergy-promoting Th2 memory 276 cells by increasing the number of their receptors for IL-25. This could explain the potential role of 277 IL-25 in the regulation of Th2 memory cells (Wang et al. 2007). IL-25 was shown to suppress 278 filaggrin expression, resulting in epithelial barrier disruption. Conversely, an impaired epithelial 279 barrier could induce the release of IL-25, which would further worsen epithelial barrier function 280 due to its negative effects on filaggrin (Hvid et al. 2011). In terms of the results of this study, 281 treatment with systemic resveratrol led to lower expression of IL-25 in the epithelium of AD-like lesions. Recent studies have indicated a central role for IL-25 in the immunopathogenesis of AD, but, to the best of our knowledge, this is the first study showing the beneficial effects of resveratrol on IL-25 expression in a mouse model of AD-like skin lesions.

Apoptosis is an essential physiologic process in the establishment and maintenance of both innate and adaptive immunity. However, it also actively participates in inflammatory and immunologic diseases such as asthma and AD (Trautmann et al. 2000). Keratinocyte apoptosis was found in situ in lesional eczematous skin and patch-test lesions of AD (Akdis et al. 2001). It was also reported 289 that interferon-gamma (IFN- $\gamma$ )-induced apoptosis in keratinocytes was increased in the skin of 
290 patients with AD compared with that in healthy subjects (Rebane et al. 2012). T-cell-mediated

291 keratinocyte apoptosis via the Fas ligand decreased the expression of the adhesion molecule E292 cadherin (Trautmann et al. 2000). This resulted in spongiosis, one of the histologic hallmarks of 293 AD (Trautmann et al. 2001b). Keratinocyte apoptosis initiates the release of chemotactic factors 294 and promotes T-cell infiltration into the epidermis. These T-cells increase the key elements of apoptosis, such as interferons and Fas (Klunker et al. 2003). The crucial role of keratinocyte apoptosis in inflammation makes it a highly attractive therapeutic target for the treatment of AD. Because of this, we hypothesized that systemic resveratrol treatment might exert antiinflammatory effects by acting on keratinocytes.

299

300

301

302

303

304

305

306

307

308

309

310

311

312

313

314

315

316

317

318

319

The aspartate-specific cysteine protease (caspase) cascade is considered the main pathway by which apoptosis is orchestrated. The most prevalent protease in the cell is caspase- 3 . This caspase is the central executioner caspase, which is responsible for the majority of the effects in cellular death (Zimmermann \& Green 2001). It was demonstrated that dexamethasone inhibited caspase-3 and caspase-7 and suppressed epithelial apoptosis. Blockage of apoptosis is one of the possible anti-inflammatory effects of steroids (Trautmann et al. 2001a). Keratinocytes are vulnerable to caspase-dependent apoptosis in response to IFN- $\gamma$ when the Fas receptor levels increase to a certain threshold (Tian et al. 2014). In this study, resveratrol treatment showed beneficial effects on keratinocyte apoptosis, which was demonstrated with lower caspase expression in AD-like lesions. This study supports previous findings showing that apoptosis has an important role in the pathogenesis of $\mathrm{AD}$ and indicates its potential importance as a target for treatment.

There are some limitations to this study. First, although we demonstrated beneficial effects of resveratrol on inflammation and apoptosis, we could not reveal the molecular pathways by which resveratrol acts on the epithelium of AD-like lesions. Inhibition of the expression of NFKB is a possible common pathway because this transcription factor both activates the cytokines involved in Th2 inflammation and regulates the genes affecting apoptosis (Barkett \& Gilmore 1999; Makarov 2000). In addition, the expression of NFkB has been found to be increased in the epithelium in chronic inflammatory diseases such as asthma (Donnelly et al. 2004). Ren et al. demonstrated the suppressor effects of resveratrol on NFkB signaling(Ren et al. 2013). Even we could not make a clear connection with $\mathrm{T}$ cell response and apoptosis, the inhibitor effects of resveratrol on NFKB expression might resulted anti-inflammatory and anti-apoptotic effects in this 
320 AD-like murine model. Moreover, Yong-Hong et. al. showed that low dose resveratrol treatment

321 led to a Th1 dominant immune response with enhanced expression of IL-2, IFN- $\gamma$ and IL-12(Feng

322 et al. 2002). However, we could not show the effect of resveratrol on theTh-1 derived cytokines

323 which should be taken into account in future experimental studies. Second,two blind histologists

324 evaluated epithelial thickness in order to avoid a potential bias in our study but a marker for cell

325 proliferation such as Kİ-67 protein could give a more conclusive data in this aspect(Scholzen et

326 al. 2002). Third, this study was conducted on mice and the findings cannot be reliably extrapolated

327 to $\mathrm{AD}$ in humans.

\section{Conclusion}

329

330

331

332

333

334

335

336

337

338

339

340

341

342

343

344 345

In conclusion, our data suggest that systemic resveratrol treatment exerts anti-inflammatory and antiapoptotic effects in a murine model of AD-like lesions. Although it is too early to draw definitive conclusions, our data indicate that resveratrol may be therapeutically beneficial to improve epithelium-derived allergic responses. Specifically, it may be effective at suppressing the very first step in inflammation.

\section{References}

Akdis M, Trautmann A, Klunker S, Blaser K, and Akdis CA. 2001. Cytokine network and dysregulated apoptosis in atopic dermatitis. Acta Odontol Scand 59:178-182.

Barkett M, and Gilmore TD. 1999. Control of apoptosis by Rel/NF-kappaB transcription factors. Oncogene 18:6910-6924. 10.1038/sj.onc.1203238

Bieber T. 2008. Atopic dermatitis. N Engl J Med 358:1483-1494. 10.1056/NEJMra074081

$358 / 14 / 1483$ [pii]

Boguniewicz M, and Leung DY. 2011. Atopic dermatitis: a disease of altered skin barrier and immune dysregulation. Immunol Rev 242:233-246. 10.1111/j.1600-065X.2011.01027.x 
346 Brandt EB, and Sivaprasad U. 2011. Th2 Cytokines and Atopic Dermatitis. J Clin Cell Immunol 347 2. $10.4172 / 2155-9899.1000110$

348 Cevikbas F, and Steinhoff M. 2012. IL-33: a novel danger signal system in atopic dermatitis. J 349 Invest Dermatol 132:1326-1329. 10.1038/jid.2012.66

350 Cianferoni A, and Spergel J. 2014. The importance of TSLP in allergic disease and its role as a 351 potential therapeutic target. Expert Rev Clin Immunol 10:1463-1474. $35210.1586 / 1744666 X .2014 .967684$

353 Dhar S, Seth J, and Parikh D. 2014. Systemic side-effects of topical corticosteroids. Indian J 354 Dermatol 59:460-464. 10.4103/0019-5154.139874

355 Donnelly LE, Newton R, Kennedy GE, Fenwick PS, Leung RH, Ito K, Russell RE, and Barnes PJ. 356 2004. Anti-inflammatory effects of resveratrol in lung epithelial cells: molecular mechanisms. Am 357 J Physiol Lung Cell Mol Physiol 287:L774-783. 10.1152/ajplung.00110.2004

358 Dumortier A, Durham AD, Di Piazza M, Vauclair S, Koch U, Ferrand G, Ferrero I, Demehri S, 359 Song LL, Farr AG, Leonard WJ, Kopan R, Miele L, Hohl D, Finke D, and Radtke F. 2010. Atopic 360 dermatitis-like disease and associated lethal myeloproliferative disorder arise from loss of Notch 361 signaling in the murine skin. PLoS One 5:e9258. 10.1371/journal.pone.0009258

362 Esche C, de Benedetto A, and Beck LA. 2004. Keratinocytes in atopic dermatitis: inflammatory 363 signals. Curr Allergy Asthma Rep 4:276-284.

364 Feng YH, Zhou WL, Wu QL, Li XY, Zhao WM, and Zou JP. 2002. Low dose of resveratrol 365 enhanced immune response of mice. Acta Pharmacol Sin 23:893-897.

366 Fort MM, Cheung J, Yen D, Li J, Zurawski SM, Lo S, Menon S, Clifford T, Hunte B, Lesley R, 367 Muchamuel T, Hurst SD, Zurawski G, Leach MW, Gorman DM, and Rennick DM. 2001. IL-25 368 induces IL-4, IL-5, and IL-13 and Th2-associated pathologies in vivo. Immunity 15:985-995.

369 Han NR, Kang SW, Moon PD, Jang JB, Kim HM, and Jeong HJ. 2014a. Genuine traditional 370 Korean medicine, Naju Jjok (Chung-Dae, Polygonum tinctorium) improves 2,4371 dinitrofluorobenzene-induced atopic dermatitis-like lesional skin. Phytomedicine 21:453-460. 372 10.1016/j.phymed.2013.09.021 
373 Han NR, Moon PD, Kim HM, and Jeong HJ. 2014b. Tryptanthrin ameliorates atopic dermatitis

374 through down-regulation of TSLP. Arch Biochem Biophys 542:14-20. 10.1016/j.abb.2013.11.010

375 Han SY, Bae JY, Park SH, Kim YH, Park JH, and Kang YH. 2013. Resveratrol inhibits IgE376 mediated basophilic mast cell degranulation and passive cutaneous anaphylaxis in mice. J Nutr 377 143:632-639. 10.3945/jn.112.173302

378 Hanifin JM, Thurston M, Omoto M, Cherill R, Tofte SJ, and Graeber M. 2001. The eczema area 379 and severity index (EASI): assessment of reliability in atopic dermatitis. EASI Evaluator Group. 380 Exp Dermatol 10:11-18.

Harikumar KB, and Aggarwal BB. 2008. Resveratrol: a multitargeted agent for age-associated 383 chronic diseases. Cell Cycle 7:1020-1035. 5740 [pii]

384 385

386 387 388

389

390

391

392

393 394

395 396 397 398 399

Holgate ST. 2007. The epithelium takes centre stage in asthma and atopic dermatitis. Trends Immunol 28:248-251. 10.1016/j.it.2007.04.007

Hui RL, Lide W, Chan J, Schottinger J, Yoshinaga M, and Millares M. 2009. Association between exposure to topical tacrolimus or pimecrolimus and cancers. Ann Pharmacother 43:1956-1963. 10.1345/aph.1M278

Hunninghake GM, Soto-Quiros ME, Avila L, Kim HP, Lasky-Su J, Rafaels N, Ruczinski I, Beaty TH, Mathias RA, Barnes KC, Wilk JB, O'Connor GT, Gauderman WJ, Vora H, Baurley JW, Gilliland F, Liang C, Sylvia JS, Klanderman BJ, Sharma SS, Himes BE, Bossley CJ, Israel E, Raby BA, Bush A, Choi AM, Weiss ST, and Celedon JC. 2010. TSLP polymorphisms are associated with asthma in a sex-specific fashion. Allergy 65:1566-1575. 10.1111/j.13989995.2010 .02415$.

Hvid M, Vestergaard C, Kemp K, Christensen GB, Deleuran B, and Deleuran M. 2011. IL-25 in atopic dermatitis: a possible link between inflammation and skin barrier dysfunction? J Invest Dermatol 131:150-157. 10.1038/jid.2010.277

Imai Y, Yasuda K, Sakaguchi Y, Haneda T, Mizutani H, Yoshimoto T, Nakanishi K, and Yamanishi K. 2013. Skin-specific expression of IL-33 activates group 2 innate lymphoid cells and 
400 elicits atopic dermatitis-like inflammation in mice. Proc Natl Acad Sci U S A 110:13921-13926. $401 \quad 10.1073 /$ pnas. 1307321110

402 Johnson JJ, Nihal M, Siddiqui IA, Scarlett CO, Bailey HH, Mukhtar H, and Ahmad N. 2011. 403 Enhancing the bioavailability of resveratrol by combining it with piperine. Mol Nutr Food Res 404 55:1169-1176. 10.1002/mnfr.201100117

405

406

Karuppagounder V, Arumugam S, Thandavarayan RA, Pitchaimani V, Sreedhar R, Afrin R, 407 Harima M, Suzuki H, Nomoto M, Miyashita S, Suzuki K, and Watanabe K. 2014. Resveratrol 408 attenuates HMGB1 signaling and inflammation in house dust mite-induced atopic dermatitis in 409 mice. Int Immunopharmacol 23:617-623. 10.1016/j.intimp.2014.10.014

Kim SW, Kim DW, Khalmuratova R, Kim JH, Jung MH, Chang DY, Shin EC, Lee HK, Shin HW, Rhee CS, Jeon SY, and Min YG. 2013. Resveratrol prevents development of eosinophilic rhinosinusitis with nasal polyps in a mouse model. Allergy 68:862-869. 10.1111/all.12132

413 Klunker S, Trautmann A, Akdis M, Verhagen J, Schmid-Grendelmeier P, Blaser K, and Akdis 414 CA. 2003. A second step of chemotaxis after transendothelial migration: keratinocytes undergoing 415 apoptosis release IFN-gamma-inducible protein 10, monokine induced by IFN-gamma, and IFN416 gamma-inducible alpha-chemoattractant for $\mathrm{T}$ cell chemotaxis toward epidermis in atopic 417 dermatitis. J Immunol 171:1078-1084.

418 Lee BW, and Detzel PR. 2015. Treatment of childhood atopic dermatitis and economic burden of 419 illness in Asia Pacific countries. Ann Nutr Metab 66 Suppl 1:18-24. 10.1159/000370221

420 Lee M, Kim S, Kwon OK, Oh SR, Lee HK, and Ahn K. 2009. Anti-inflammatory and anti421 asthmatic effects of resveratrol, a polyphenolic stilbene, in a mouse model of allergic asthma. Int 422 Immunopharmacol 9:418-424. 10.1016/j.intimp.2009.01.005

423 Leung DY, Boguniewicz M, Howell MD, Nomura I, and Hamid QA. 2004. New insights into 424 atopic dermatitis. J Clin Invest 113:651-657. 10.1172/JCI21060 
425 Li YZ, Lu XY, Jiang W, and Li LF. 2013. Anti-inflammatory effect of qingpeng ointment in atopic 426 dermatitis-like murine model. Evid Based Complement Alternat Med 2013:907016. $42710.1155 / 2013 / 907016$

428 Makarov SS. 2000. NF-kappaB as a therapeutic target in chronic inflammation: recent advances. 429 Mol Med Today 6:441-448.

430 Micili SC, Goker A, Sayin O, Akokay P, and Ergur BU. 2013. The effect of lipoic acid on wound 431 healing in a full thickness uterine injury model in rats. J Mol Histol 44:339-345. 10.1007/s10735$432 \quad 013-9485-8$

433 Rebane A, Zimmermann M, Aab A, Baurecht H, Koreck A, Karelson M, Abram K, Metsalu T, 434 Pihlap M, Meyer N, Folster-Holst R, Nagy N, Kemeny L, Kingo K, Vilo J, Illig T, Akdis M, 435 Franke A, Novak N, Weidinger S, and Akdis CA. 2012. Mechanisms of IFN-gamma-induced 436 apoptosis of human skin keratinocytes in patients with atopic dermatitis. J Allergy Clin Immunol 437 129:1297-1306. 10.1016/j.jaci.2012.02.020

438 Reddy PH. 2011. Mitochondrial Dysfunction and Oxidative Stress in Asthma: Implications for 439 Mitochondria-Targeted Antioxidant Therapeutics. Pharmaceuticals (Basel) 4:429-456. $440 \quad 10.3390 / \mathrm{ph} 4030429$

441 Ren Z, Wang L, Cui J, Huoc Z, Xue J, Cui H, Mao Q, and Yang R. 2013. Resveratrol inhibits NF$442 \mathrm{kB}$ signaling through suppression of p65 and IkappaB kinase activities. Pharmazie 68:689-694.

443 Ricci G, Dondi A, Patrizi A, and Masi M. 2009. Systemic therapy of atopic dermatitis in children. 444 Drugs 69:297-306. 10.2165/00003495-200969030-00005

445 Royce SG, Dang W, Yuan G, Tran J, El Osta A, Karagiannis TC, and Tang ML. 2011. Resveratrol 446 has protective effects against airway remodeling and airway hyperreactivity in a murine model of 447 allergic airways disease. Pathobiol Aging Age Relat Dis 1. 10.3402/PBA.v1i0.7134

448 Savinko T, Matikainen S, Saarialho-Kere U, Lehto M, Wang G, Lehtimaki S, Karisola P, Reunala 449 T, Wolff H, Lauerma A, and Alenius H. 2012. IL-33 and ST2 in atopic dermatitis: expression 450 profiles and modulation by triggering factors. $\mathrm{J}$ Invest Dermatol 132:1392-1400. $451 \quad 10.1038 /$ jid.2011.446 
452 Scholzen T, Endl E, Wohlenberg C, van der Sar S, Cowell IG, Gerdes J, and Singh PB. 2002. The

453 Ki-67 protein interacts with members of the heterochromatin protein 1 (HP1) family: a potential 454 role in the regulation of higher-order chromatin structure. J Pathol 196:135-144. $45510.1002 /$ path. 1016

456 Sharma P, Huq AU, and Singh R. 2014. Cypermethrin-induced reproductive toxicity in the rat is 457 prevented by resveratrol. J Hum Reprod Sci 7:99-106. 10.4103/0974-1208.138867

458 Shimizu M, Matsuda A, Yanagisawa K, Hirota T, Akahoshi M, Inomata N, Ebe K, Tanaka K, 459 Sugiura H, Nakashima K, Tamari M, Takahashi N, Obara K, Enomoto T, Okayama Y, Gao PS, 460 Huang SK, Tominaga S, Ikezawa Z, and Shirakawa T. 2005. Functional SNPs in the distal 461 promoter of the ST2 gene are associated with atopic dermatitis. Hum Mol Genet 14:2919-2927. $46210.1093 / \mathrm{hmg} / \mathrm{ddi} 323$

463 Soumelis V, Reche PA, Kanzler H, Yuan W, Edward G, Homey B, Gilliet M, Ho S, Antonenko 464 S, Lauerma A, Smith K, Gorman D, Zurawski S, Abrams J, Menon S, McClanahan T, de Waal465 Malefyt Rd R, Bazan F, Kastelein RA, and Liu YJ. 2002. Human epithelial cells trigger dendritic 466 cell mediated allergic inflammation by producing TSLP. Nat Immunol 3:673-680. 10.1038/ni805

467 Tian BP, Zhou HB, Xia LX, Shen HH, and Ying S. 2014. Balance of apoptotic cell death and 468 survival in allergic diseases. Microbes Infect 16:811-821. 10.1016/j.micinf.2014.07.004

469 Trautmann A, Akdis M, Kleemann D, Altznauer F, Simon HU, Graeve T, Noll M, Brocker EB, 470 Blaser K, and Akdis CA. 2000. T cell-mediated Fas-induced keratinocyte apoptosis plays a key 471 pathogenetic role in eczematous dermatitis. J Clin Invest 106:25-35. 10.1172/JCI9199

472 Trautmann A, Akdis M, Schmid-Grendelmeier P, Disch R, Brocker EB, Blaser K, and Akdis CA. 473 2001a. Targeting keratinocyte apoptosis in the treatment of atopic dermatitis and allergic contact 474 dermatitis. J Allergy Clin Immunol 108:839-846. 10.1067/mai.2001.118796

475 Trautmann A, Altznauer F, Akdis M, Simon HU, Disch R, Brocker EB, Blaser K, and Akdis CA. 476 2001b. The differential fate of cadherins during T-cell-induced keratinocyte apoptosis leads to 477 spongiosis in eczematous dermatitis. J Invest Dermatol 117:927-934. 10.1046/j.0022$478 \quad 202 x .2001 .01474 . x$ 
479 Wang YH, Angkasekwinai P, Lu N, Voo KS, Arima K, Hanabuchi S, Hippe A, Corrigan CJ, Dong 480 C, Homey B, Yao Z, Ying S, Huston DP, and Liu YJ. 2007. IL-25 augments type 2 immune 481 responses by enhancing the expansion and functions of TSLP-DC-activated Th2 memory cells. J 482 Exp Med 204:1837-1847. 10.1084/jem.20070406

483 Weidinger S, and Novak N. 2015. Atopic dermatitis. Lancet. 10.1016/S0140-6736(15)00149-X

484 Werfel T. 2009. The role of leukocytes, keratinocytes, and allergen-specific $\operatorname{IgE}$ in the 485 development of atopic dermatitis. J Invest Dermatol 129:1878-1891. 10.1038/jid.2009.71

486 Wu Z, Uchi H, Morino-Koga S, Shi W, and Furue M. 2014. Resveratrol inhibition of human 487 keratinocyte proliferation via SIRT1/ARNT/ERK dependent downregulation of aquaporin 3. J 488 Dermatol Sci 75:16-23. 10.1016/j.jdermsci.2014.03.004

489 Yoo J, Omori M, Gyarmati D, Zhou B, Aye T, Brewer A, Comeau MR, Campbell DJ, and Ziegler 490 SF. 2005. Spontaneous atopic dermatitis in mice expressing an inducible thymic stromal 491 lymphopoietin transgene specifically in the skin. J Exp Med 202:541-549. 10.1084/jem.20041503

492 Yuksel H, Yilmaz O, Baytur YB, and Ozbilgin K. 2008. Prenatal administration of granulocyte493 macrophage colony-stimulating factor increases mesenchymal vascular endothelial growth factor 494 expression and maturation in fetal rat lung. Exp Lung Res 34:550-558. $49510.1080 / 01902140802341736$

496 Zimmermann KC, and Green DR. 2001. How cells die: apoptosis pathways. J Allergy Clin 497 Immunol 108:S99-103.

498

499

500

501

502

503 
1

Schematic presentation of experimental procedure

(A)Experimental procedure in control group (B) Experimental procedure in vehicle control group (C) Experimental procedure in resveratrol treatment group.DNFB, 2,4-

Dinitrophenylbenzene; DMSO,dimethyl sulfoxide;IL, interleukin; TSLP, thymic stromal lymphopoietin 


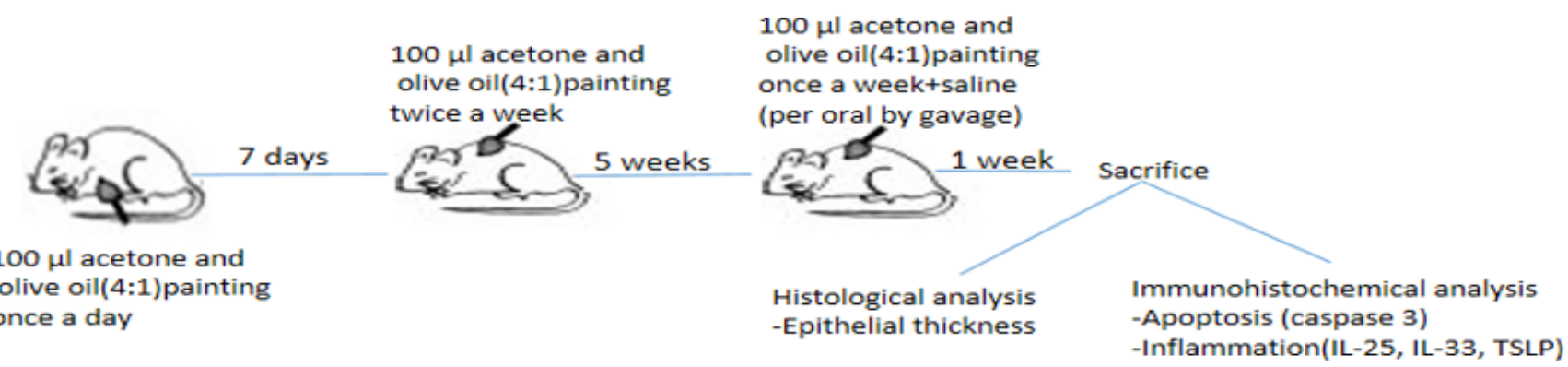

B

$100 \mu \mathrm{LNFB}(0.2 \%)$

(dissolved in acetone and olive oil(4:1))painting twice a week
$100 \mu \mathrm{IDNFB}$

$(0.2 \%)$ (dissolved in acetone and olive oil(4:1)) painting

once a week+100 $\mu$ l DMSO(per oral by gavage)

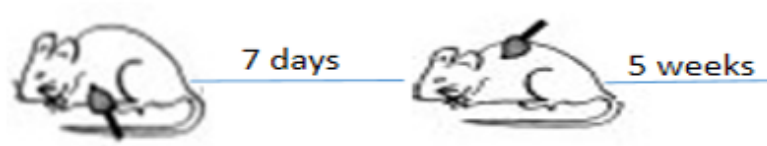

$100 \mu \mathrm{l}$ DNFB(0.5\%)

(dissolved in acetone and olive oil (4:1)) painting once a day

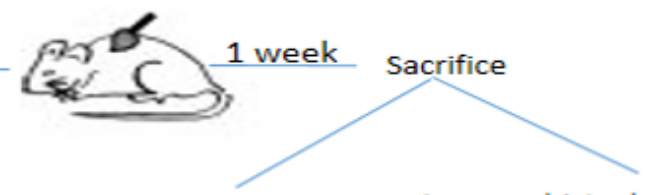

Histological analysis -Epithelial thickness
Immunohistochemical analysis -Apoptosis (caspase 3 )

-Inflammation(IL-25, IL-33, TSLP)

C

$100 \mu \mathrm{I} \mathrm{DNFB}(0.2 \%)$

(dissolved in acetone and olive oil(4:1))painting

twice a week
$100 \mu \mathrm{l}$ DNFB $(0.2 \%)$ (dissolved in acetone and olive oil(4:1)) painting once a week+30 mg/ kg/day resveratrol dissolved in $100 \mu \mathrm{l}$ DMSO (per oral by gavage) during 6th week

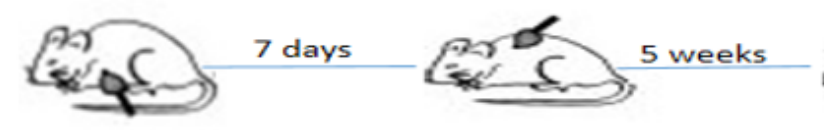

$100 \mu \mathrm{IDNFB}(0.5 \%)$ (dissolved in acetone and olive oil (4:1)) painting once a day

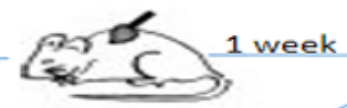

Histological analysis -Epithelial thickness
Sacrifice

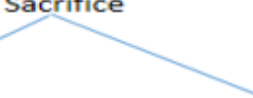

Immunohistochemical analysis -Apoptosis (caspase 3 )

-Inflammation(IL-25, IL-33, TSLP) 
2

Representative pictures of dermatitis in groups after a 1-week treatment

(A)Control group 1.Erythema/haemorrhage:1/3; 2.Scaling/dryness:0/3; 3.Edema:0/3;

4.Excoriation/erosion:0/3.DS:1 (B) Vehicle control group 1.Erythema/haemorrhage:1/3;

2.Scaling/dryness:3/3; 3.Edema:1/3; 4.Excoriation/erosion:3/3.DS:8(C)Resveratrol treatment

1.Erythema/haemorrhage:1/3; 2.Scaling/dryness:1/3;

3.Edema:0/3;4.Excoriation/erosion:2/3.DS:4.DS;dermatitis score

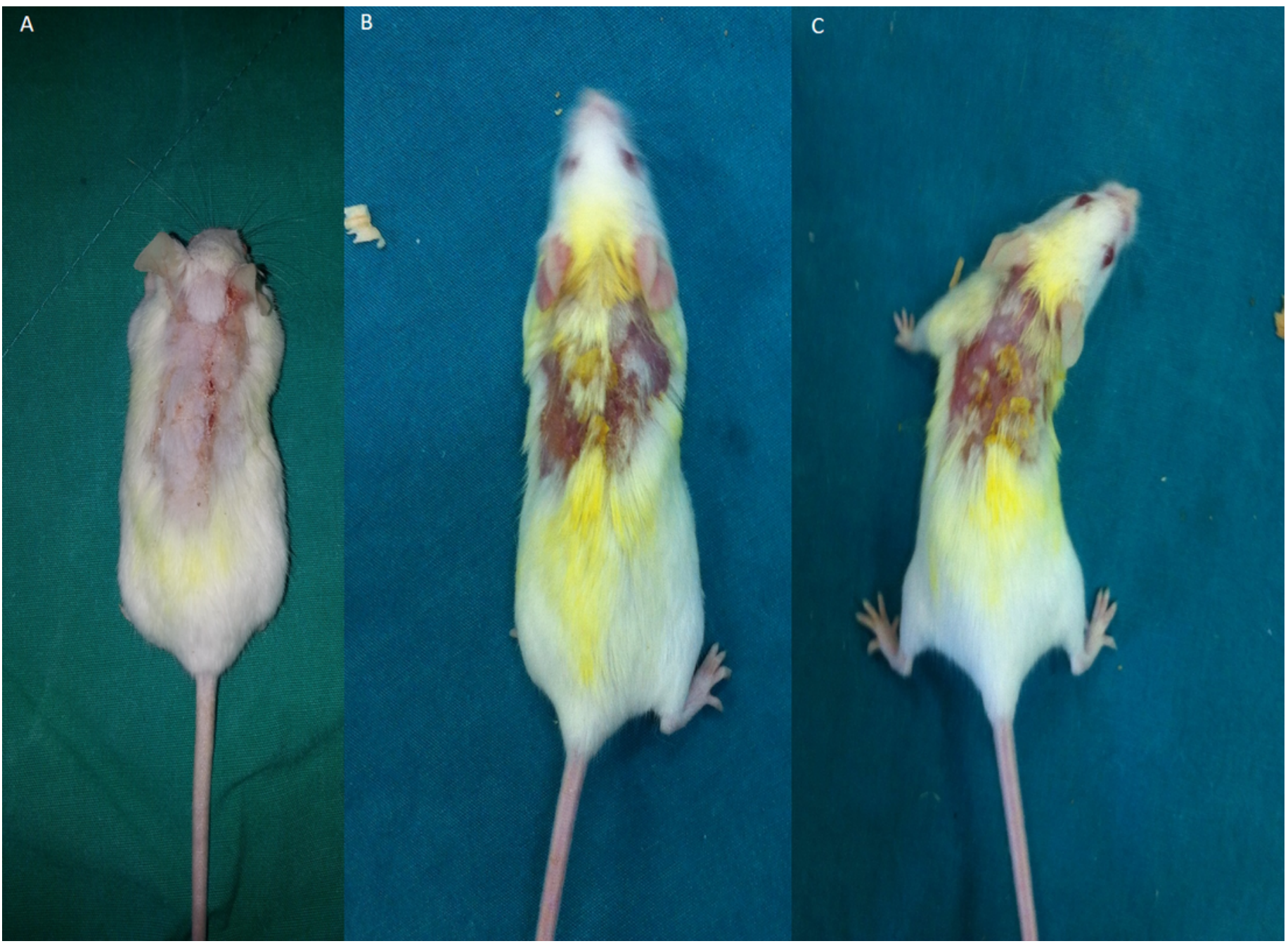


3

Representative H\&E staining of skin tissues in groups after 1-week treatment.

(A) Control group; Normal regular epithelium (B) Vehicle control group;Thickening of the epidermis and epidermal irregularity (C) Resveratrol treatment; A minimally irregular epithelium accompanying epithelial thickness

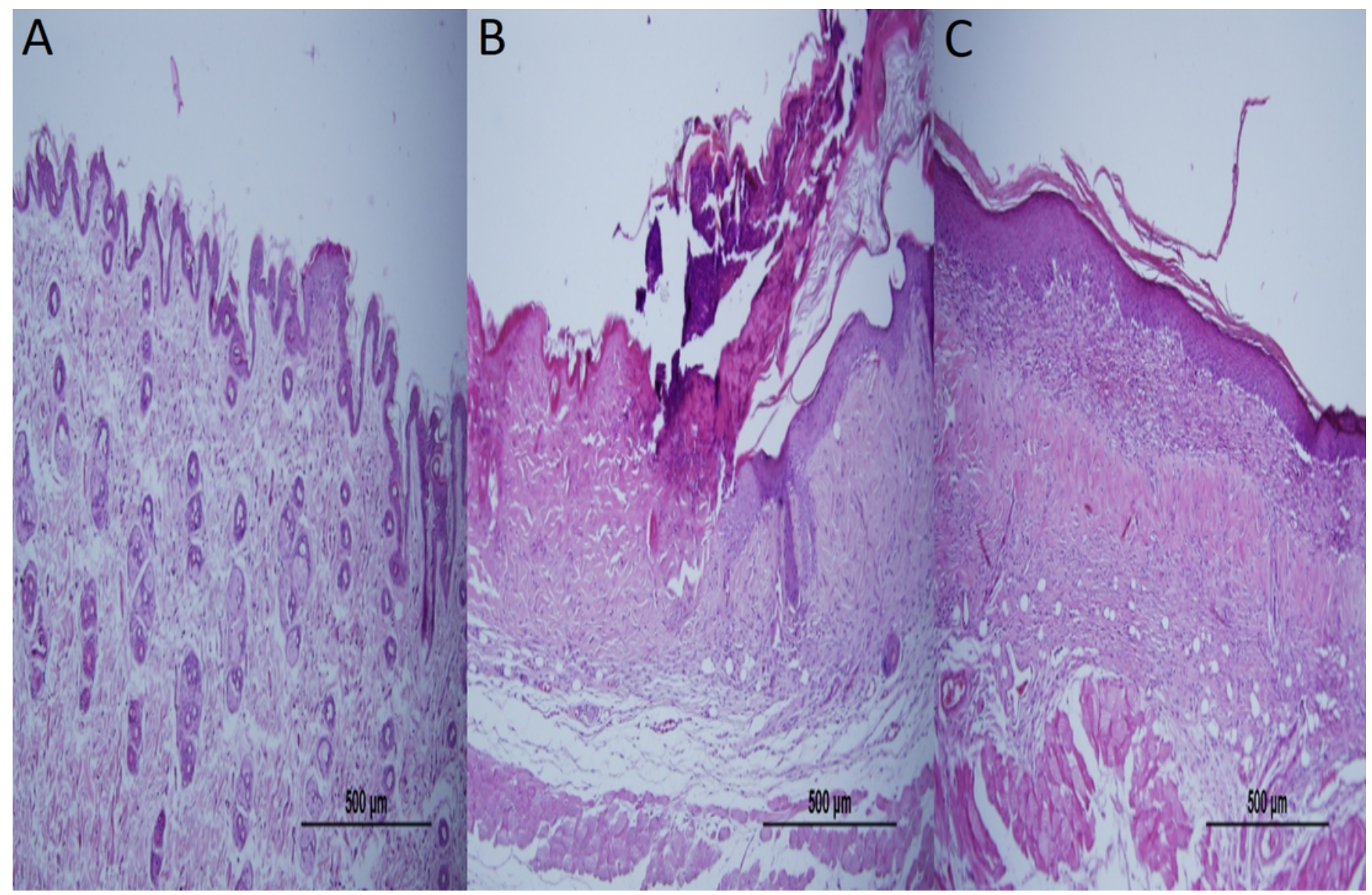


Figure 4 (on next page)

Boxplot of the epidermal thickness $(\mu \mathrm{m})$ in groups. 


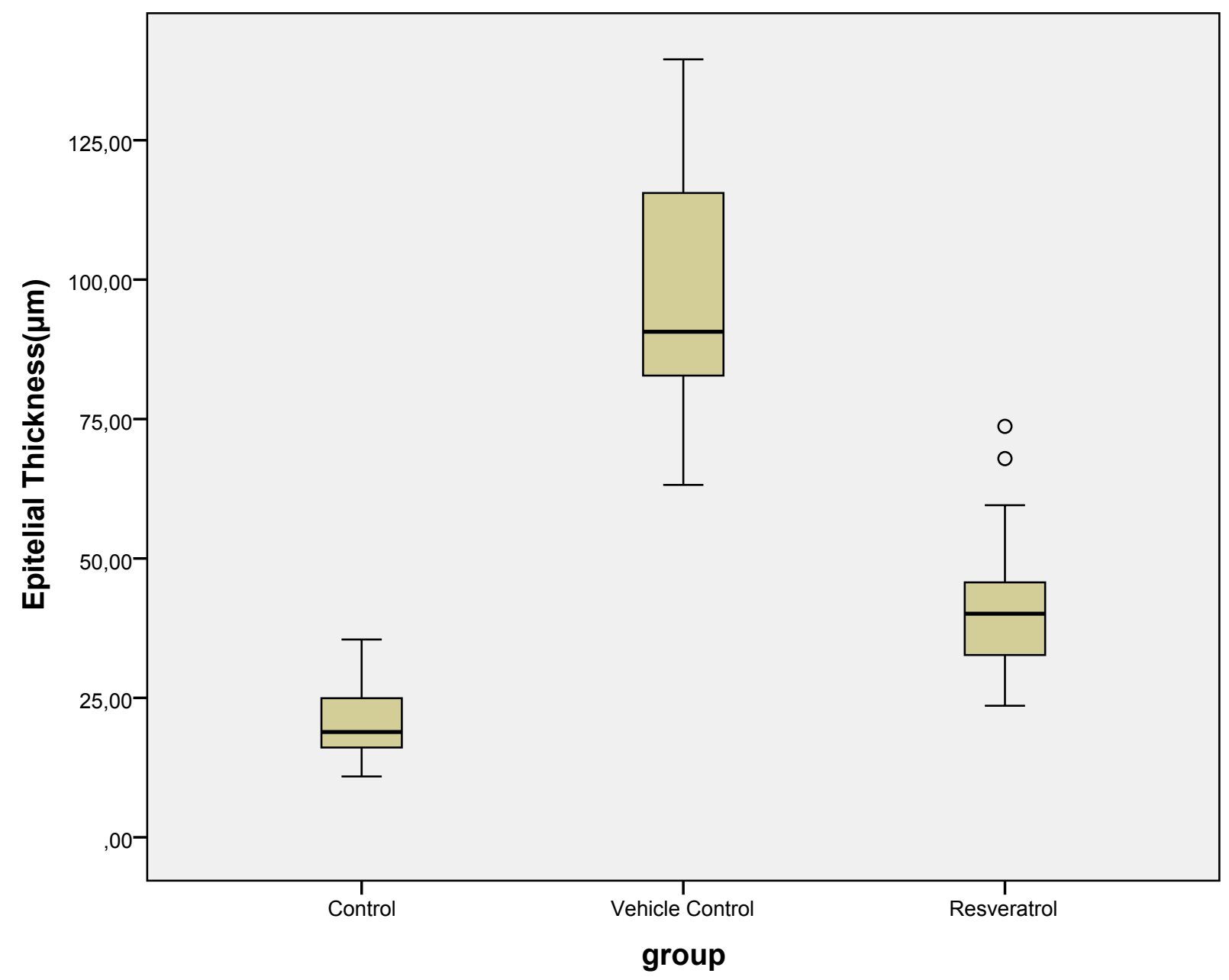

Page 1 


\section{5}

Comparison ofimmunohistochemical analysis between groups

Comparison of immunohistochemical analysis between groups .(A,D,G,J) Control

group; (B) Vehicle control group; yellow arrows shows prominent immunostaining for IL-25 (E)

Vehicle control group; yellow arrows shows prominent immunostaining for IL-33 (H) Vehicle control group; yellow arrows shows prominent immunostaining for TSLP (K) Vehicle control group; yellow arrows shows prominent immunostaining for caspase-3 (C) Resveratrol treatment group; yellow arrows shows lower immunostaining for IL-25 (F) Resveratrol treatment group; yellow arrows shows lower immunostaining for IL-33 (I) Resveratrol treatment group; yellow arrows shows lower immunostaining for TSLP (L) Resveratrol treatment group; yellow arrows shows lower immunostaining for caspase-3.The dashed lines indicate the approximate location of the epidermal basement membrane.IL, interleukin; TSLP, thymic stromal lymphopoietin 


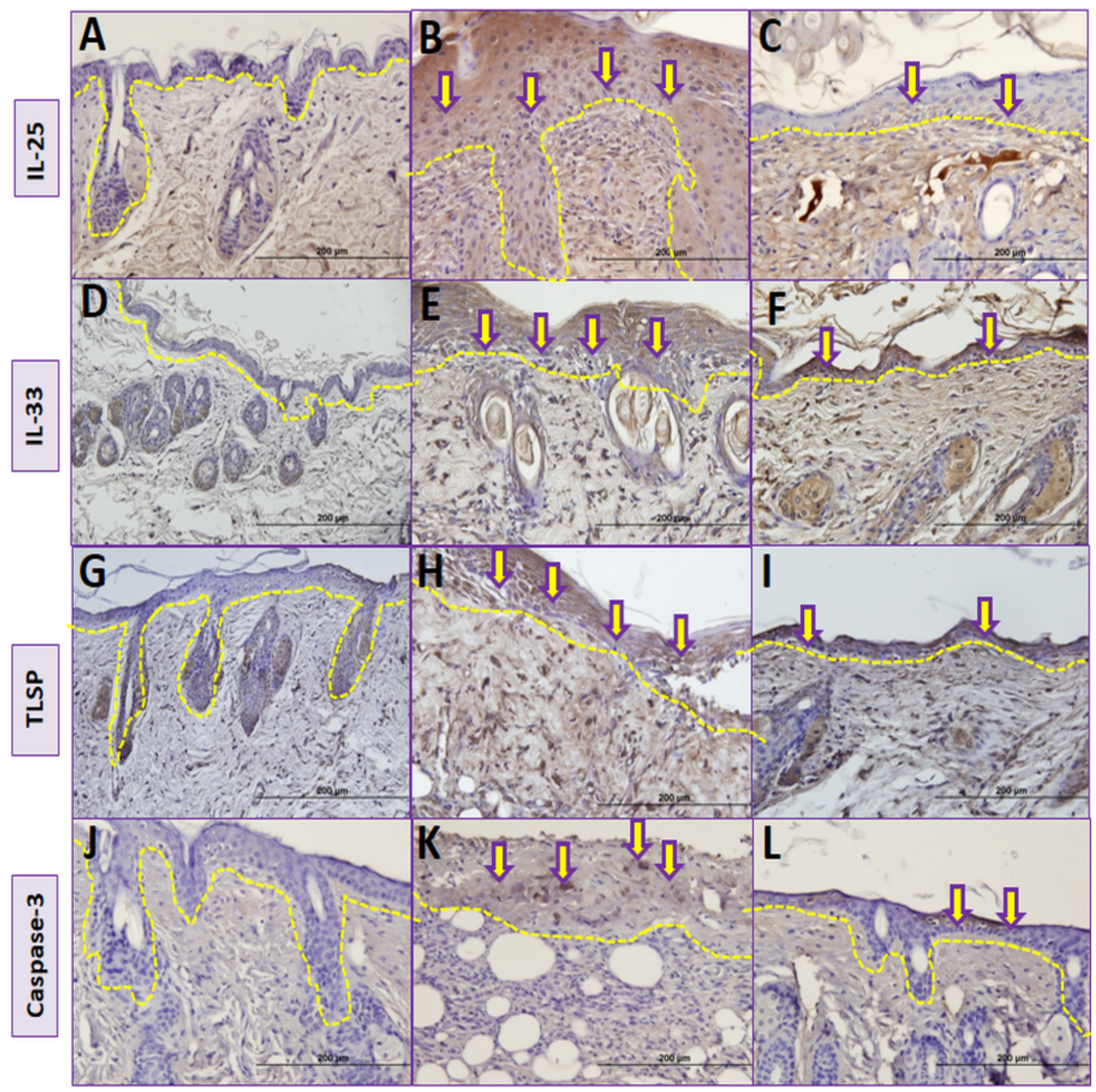




\section{Figure 6 (on next page)}

Boxplot of the IL-25,IL-33 and TSLP H scores in the various groups.

IL, interleukin; TSLP, thymic stromal lymphopoietin 


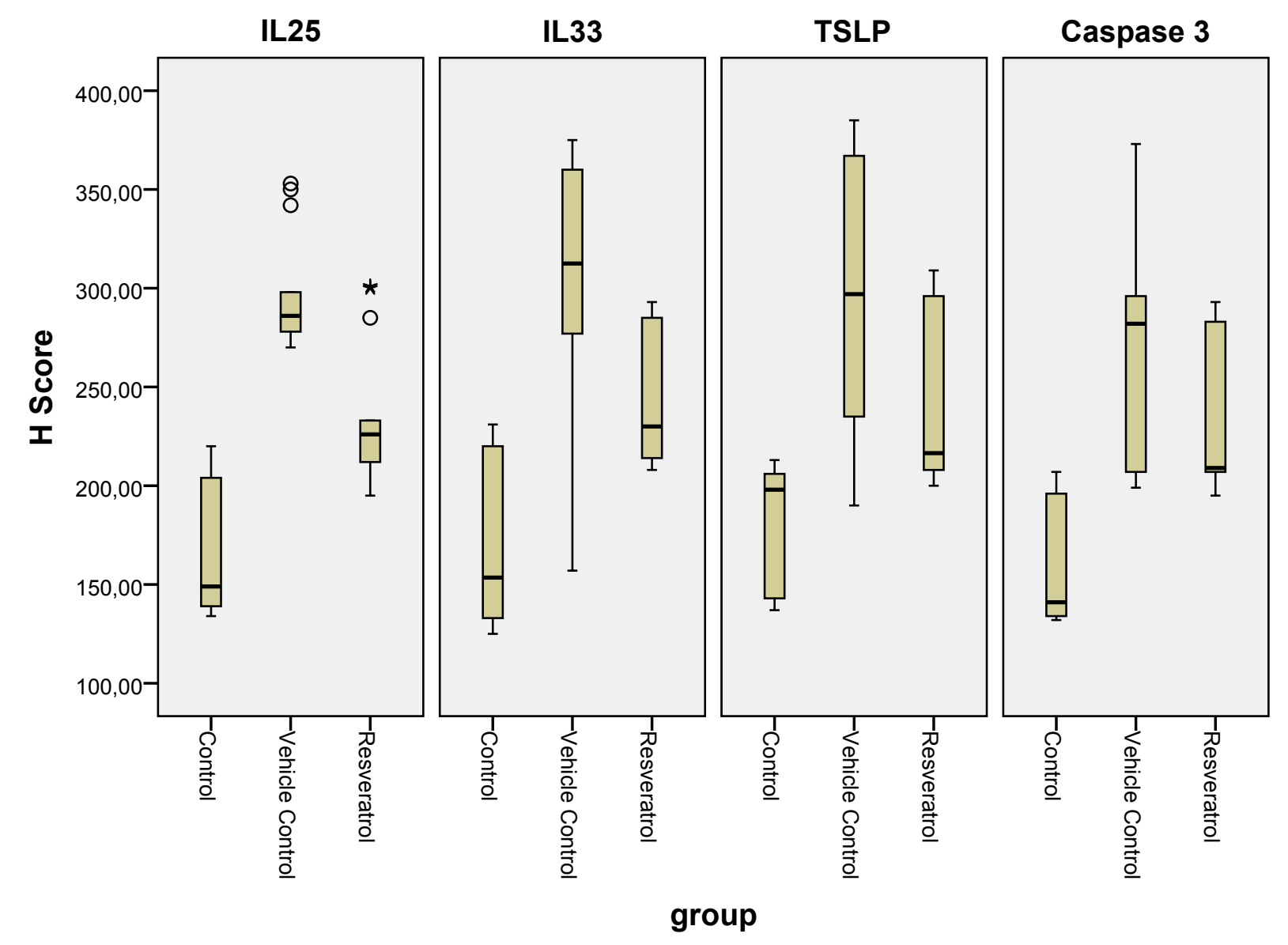

Page 1 


\section{Table $\mathbf{1}$ (on next page)}

Comparison of dermatitis scores in study groups.

Values are expressed as the median (25 75 percentile). Two group comparisons were made using Mann Whitney U test; IQR, Interquartile Range; SD, Standard deviation 
1 Table 1.Comparison of dermatitis scores in study groups

\begin{tabular}{|l|c|c|c|c|}
\hline Variables & $\begin{array}{c}\text { Group I } \\
\text { Control }\end{array}$ & $\begin{array}{c}\text { Group II } \\
\text { Vehicle Control }\end{array}$ & $\begin{array}{c}\text { Group III } \\
\text { Resveratrol }\end{array}$ & P value $^{\text {a }}$ \\
\hline & Mean \pm SD & Mean \pm SD & Mean $\pm S D$ & \\
Median(IQR) & Median(IQR) & $8.42 \pm 0.79$ & 0.001 \\
& $0.57 \pm 0.53^{\text {b }}$ & $8.29 \pm 0.49$ & 8.0 & \\
\hline $5^{\text {th }}$ week & 1.0 & 8.0 & $(8.0-9.0)$ & \\
& $(0.0-1.0)$ & $(8.0-9.0)$ & $5.14 \pm 1.68^{\text {c }}$ & 0.001 \\
& $0.57 \pm 0.53$ & $8.86 \pm 0.69$ & 4.0 & \\
\hline $6^{\text {th }}$ week & 1.0 & 8.0 & $(4.0-7.0)$ & \\
& $(0.0-1.0)$ & $(8.0-10.0)$ & & \\
\hline
\end{tabular}

2 a $\mathrm{P}$ value was calculated by Kruskall Wallis $\mathrm{H}$ test

3 bSignificantly lower compared to Group II and Group III

4 c Significantly lower compared to Group II

5

6 Values are expressed as the median (25-75 percentile). Two group comparisons were made using

7 Mann Whitney U test; IQR, Interquartile Range; SD, Standard deviation

8

9

10

11

12 


\section{Table 2 (on next page)}

Comparison of H scores in study groups.

Values are expressed as the median (25 75 percentile). P values were calculated using the Kruskal Wallis and Mann Whitney U test. IL, interleukin; TSLP, thymic stromal lymphopoietin. 
1 Table 2.Comparison of $\mathrm{H}$ scores in study groups

\begin{tabular}{|l|c|c|c|c|}
\hline Variables & $\begin{array}{c}\text { Group I } \\
\text { Control }\end{array}$ & $\begin{array}{c}\text { Group II } \\
\text { Vehicle Control }\end{array}$ & $\begin{array}{c}\text { Group III } \\
\text { Resveratrol }\end{array}$ & P value $^{\text {a }}$ \\
\hline & Mean \pm SD & Mean \pm SD & Mean $\pm S D$ \\
Median(IQR) & Median(IQR) & \\
\hline IL-25 & $164.85 \pm 33.37$ & $297.50 \pm 28.83^{\mathrm{b}}$ & $234.79 \pm 34.98^{\mathrm{bc}}$ & 0.001 \\
& 149 & 286 & 226 & \\
& $(138.5-206.5)$ & $(277.75-309.0)$ & $(210-246)$ & \\
\hline IL-33 & $167.21 \pm 39.48$ & $311.71 \pm 60.13^{\mathrm{b}}$ & $247.71 \pm 36.59 \mathrm{bc}$ & 0.001 \\
& 149 & 312.5 & 230 & \\
\hline TSLP & $(138.5-206.5)$ & $(276.50-312.50)$ & $(213.25-285.75)$ & \\
& $177.5 \pm 32.76$ & $301.93 \pm 69.86^{\mathrm{b}}$ & $247.5 \pm 45.30^{\mathrm{bc}}$ & 0.001 \\
& 198 & 297.92 & 216.5 & \\
\hline Caspase-3 & $(141-206)$ & $(229.75-367.25)$ & $(207.75-296.25)$ & \\
& $157.07 \pm 36.43$ & $282.42 \pm 37.41^{\mathrm{b}}$ & $214.57 \pm 22.01^{\mathrm{bc}}$ & 0.001 \\
& 134 & 288.5 & 206 & \\
\hline
\end{tabular}

2 a $\mathrm{P}$ value was calculated by Kruskall Wallis $\mathrm{H}$ test

3 bSignificantly higher compared to Group I

4 cSignificantly lower compared to Group II

5

6 Values are expressed as the median (25-75 percentile). Two group comparisons were made using

7 Mann Whitney U test. IL, interleukin; TSLP, thymic stromal lymphopoietin; IQR, Interquartile

8 Range

9

10

11 